\title{
TRATAMIENTO ENDOVASCULAR DE ANEURISMA DE BIFURCACIÓN DE LA ARTERIA CEREBRAL MEDIA
}

\author{
Rosales Bravo Luis; Hernández Gaitán, Manuel2; Cabezas Campodónico, Carlos ${ }^{3}$ y Quiroga \\ Galindo, Mónica ${ }^{3}$
}

${ }^{1}$ Division of Neurology, Hospital México, Caja Costarricense de Seguro Social. School of Medicine, Costa Rica University, San José, Costa Rica. ${ }^{2}$ Division of Neuroradiology Hospital México, Caja Costarricense de Seguro Social, School of Medicine, Costa Rica University, San José, Costa Rica. ${ }^{3}$ Division of Neurosurgery Hospital México, Caja Costarricense de Seguro Social. School of Medicine, Costa Rica University, San José, Costa Rica

Resumen: Los aneurismas cerebrales de la arteria cerebral media representan una causa frecuente de hemorragia subaracnoidea espontánea. El tratamiento quirúrgico mediante el clipaje del cuello del mismopara evitar el resangrado- tradicionalmente ha sido el tratamiento de elección. En la actualidad y dependiendo de la morfología del saco aneurismático, la relación cuello/domo y la ausencia de ramas arteriales que se originen del saco del aneurisma, hacen que sea posible el tratamiento endovascular de estos aneurismas mediante espirales de metal (coils). Con esta técnica se logra una exclusión completa del aneurisma de la circulación arterial cerebral con una muy baja tasa de recanalización y de complicaciones. El objetivo del tratamiento endovascular es excluir el aneurisma de la circulación cerebral para evitar el resangrado, reducir el riesgo de complicaciones tromboembólicas y reducir la mortalidad en este grupo de pacientes. A través de un caso clínico se muestra el tratamiento endovascular de un aneurisma sacular roto de la bifurcación de la arteria cerebral media. En la literatura médica de Costa Rica este es el primer caso reportado.

Palabras clave: aneurisma cerebral, arteria cerebral media, tratamiento endovascular 


\title{
ENDOVASCULAR TREATMENT OF A MIDDLE CEREBRAL ARTERY BIFURCATION ANEURYSM
}

\begin{abstract}
Cerebral aneurysms of the middle cerebral artery are a frequent cause of spontaneous subarachnoid hemorrhage. The surgical neck clipping-to prevent rebleeding- has traditionally been the treatment of choice. Currently, depending on the morphology of the aneurysm sac, the ratio neck / dome and the absence of arterial branches that arise from the aneurysm sac, make possible the endovascular treatment of aneurysms using coils. This technique achieves complete exclusion of the aneurysm from the cerebral blood flow with a low rate of recanalization and complications. The goal of treatment is to exclude the aneurysm from the cerebral circulation preventing the rebleeding, reduce the risk of thromboembolic complications and reduce mortality in this patient's group. Through a clinical case is showed an endovascular treatment of a ruptured sacular middle cerebral artery bifurcation aneurysm. In the Costa Rica's medical literature this is the first reported case.
\end{abstract}

Key words: cerebral aneurysm, middle cerebral artery, endovascular treatment

\section{INTRODUCCIÓN}

Although surgical treatment of ruptured and non-rupture cerebral aneurysms of the middle cerebral artery-by the neck clipping- is the preferred treatment, mainly because the relatively simple surgical access, the necessity of vascular remodeling depending on the angioarchitecture of the aneurysm and in many cases particularly when the ruptured aneurysm is associated with a large hematoma requires immediate evacuation of the intracerebral hematoma [1]. However the endovascular treatment (EVT) of cerebral aneurysms is a well accepted alternative treatment approach to surgery, with better clinical outcomes at 1 year after treatment as compared to surgical cases, according to the International Subarachnoid Aneurysm Trial (ISAT) [2]. Furthermore, the rate of periprocedural complication and the rebleeding are low. In recent years, the EVT of these aneurysms in a safe procedure with a low rate of complications and recurrence for both ruptured and non-rupture aneurysm [3]. Due to the development of new devices like intracraneal stents even MCA complexes aneuriysms can be treated with EVT with a very low rate of recanalization, thromboembolic complications and mortality [ 4 ].

\section{CASE REPORT}

A 54 years-old, right-handed, female patient with a medical history of hypertension treated with irbesartan $150 \mathrm{mg}$ p.o and hydrochlorothiazide $25 \mathrm{mg}$ p.o. daily, besides active smoker for at least 30 years was admitted to our hospital. Previous good general status, she suddenly complainted with severe headache, nausea, vomiting and also loss of consciousness for a few minutes. Her vital signs on admission were BP 160/100 mm Hg, HR 86 beats per minute, FR 12 x min, temperature 37.2 degrees Celcius. Clinically she was admitted with a Hunt-Hess Scale grade II (mild headache, mild neck stiffness and mild left 
hemiparesis).

The unenhanced brain CT showed subarachnoid bleeding mainly at the right Sylvian fissure (Fischer Scale II) (not showed). Digital subtraction cerebral angiography of the four main cerebral arteries revealed a saccular aneurysm at the bifurcation of the right MCA with approximate dimensions of $6 \mathrm{~mm} \times 5 \mathrm{~mm} \times 3 \mathrm{~mm}$ (figure

A,B).

Previous explanation to the patient and her family about the two treatment options (surgical and EVT) they decided the EVT option. Previous the procedure an informed consent for this purpose were signed. To minimize the risk of thrombotic complications during the EVT a loading dose of $300 \mathrm{mg}$ p.o of clopidogrel and $300 \mathrm{mg}$ p.o of acetylsalicylic acid were administrated through the nasogastric tube at the beginning of the procedure. It was performed under general anesthesia and systemic heparinization, with an intravenous administration of heparin 5000 UI to achieve an ACT (activating clotting time) of 300 seconds. A Foley tube was place inside the patient's bladder. Using the Seldinger technique, the right femoral artery was punctured and a $6 \mathrm{~F}$ short introducer was placed. Through a 6F Envoy ${ }^{\circledR}$ (Boston Scientific) guiding catheter with its tip positioned at the level of the petrosal segment of the right ICA and using a coaxial system, a microcatheter Excelsior $10 \AA$-SL (Boston Scientific) was advanced until the aneurysm sac through a microwire Transend-EX ® type $300 \mathrm{~cm}$ in length (Boston Scientific). Then, a sequential aneurysm embolization with coils was completed until exclude it from the cerebral circulation and to secure the rupture

site.

According to our hospital protocol, the patient was transferred to the Neurocritical Care Unit for continuous neurological monitoring. During the following hours after the endovascular intervention, the patient became drowsy and with moderate increase of left-side hemiparesis. This worsening was interpreted as a transient cerebral hypoperfusion secondary to a reactive vasospasm or some minor thromboembolic complication relate with the embolization. Through a subclavian's vein central line, volume expander was administered (Dextran 40\% 1 liter) in continuous infusion for 24 hours. Also anticoagulation with enoxaparin $80 \mathrm{mg}$ sc every 12 hours for 48 consecutive hours was started (full anticoagulation). Few hours later, the patient recovered her neurological condition prior to the procedure. Two days after the embolization, a control brain CT scan was done, it showed no tromboembolic complications on the territory of the RMCA (Figure C,D). The patient was transfer to the Rehabilitation Center to continue her physical therapy. Six months later the patient was without any neurological deficit and with a modified Ranking Scale of 0 . Two years and ten months after de embolization a brain MRA was done, it showed no recanalization of the aneurysm sac and patency of the right MCA (Figure E,F).

\section{DISCUSSION}

This case illustrates that the EVT of MCA aneurysms is a safe procedure with a low rate of immediate and late complications including the regrowing of the aneurysm'sac, and that the rate of recanalization of the aneurysm is rare, in case of the aneurysm's neck was properly packaged and not residual neck was present. The main goal of the treatment is to prevent the rebleeding, which usually occurs during the first 48 hours of the initial rupture of the aneurysm, and is a common cause of mortality and morbidity. Therefore the current trend is to treat ruptured cerebral aneurysm (EVT or surgical clipping) as soon as possible, because treatment of ruptured aneurysms within 24 hours is associated with improved clinical outcomes compared with treatment more than 24 hours. The benefit is more pronounced for coiling than clipping [5]. Although in this case the aneurysm embolization was done without the use of intracranial stent, a loading dose of aspirin $(300 \mathrm{mg}$ ) and clopidogrel $(300 \mathrm{mg}$ ) was administered during the procedure to prevent delate ischemia and thromboembolic complications due mainly to the anatomical location of the aneurysm, besides the dual antiplatelet treatment was continued for 6 consecutive months. A postoperative systemic anticoagulation was maintained with subcutaneous enoxaparin for 48 consecutive hours due to the transient clinical deterioration of the patient's neurological condition. The use of systemic anticoagulation and antiplatelet management is very variable in terms of dose and duration, but is more common in patients undergoing EVT in which intracranial stent must be used as in the case of blisterlike aneurysms, which are a rare type of intracranial aneurysm difficult to treat both surgically and endovascularly [6]. 

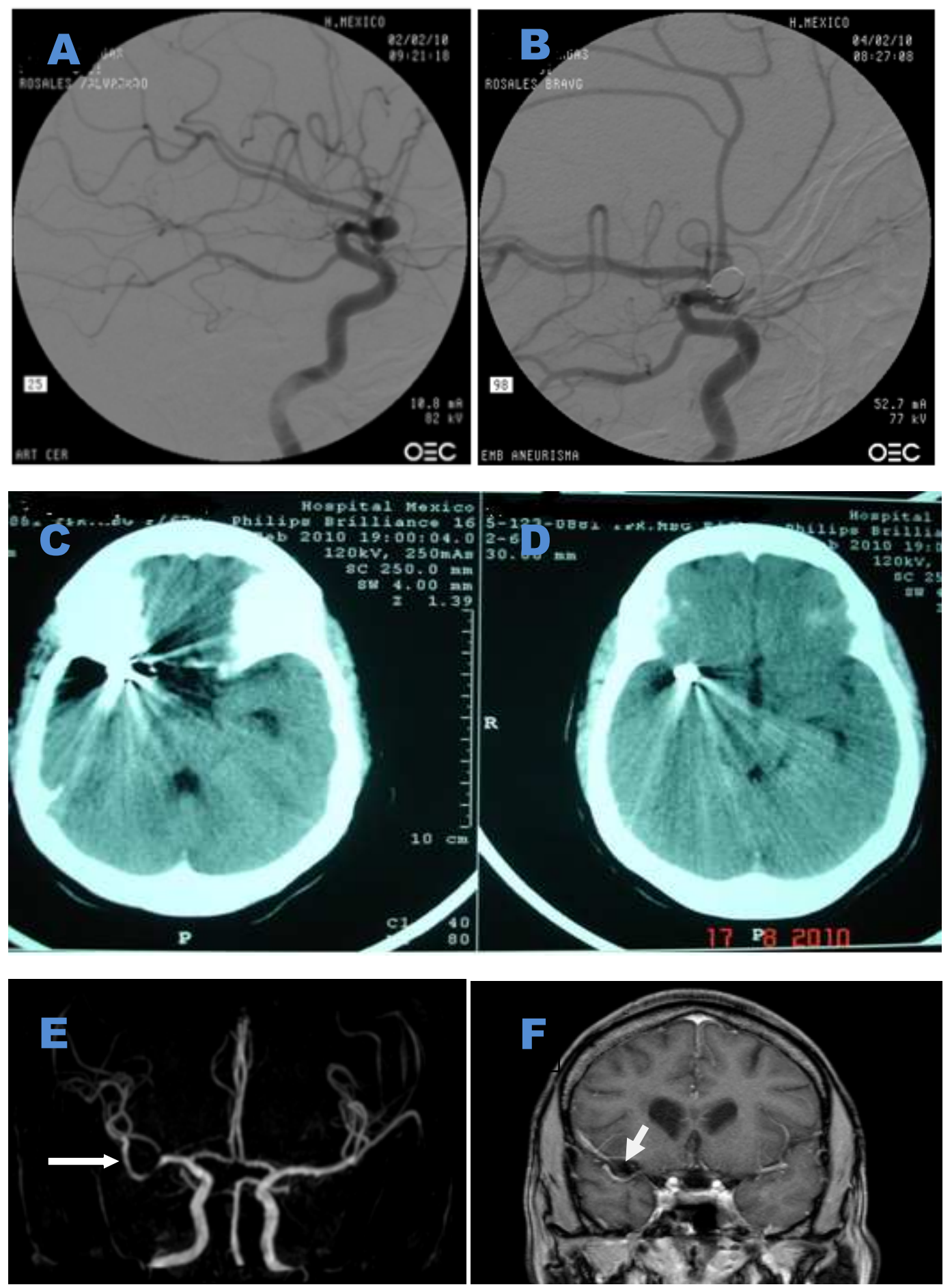

Figure 1. (A and B) digital subtraction cerebral angiography (lateral projection) pre- and post EVT shows a saccular aneurysm at the bifurcation of the RMCA. There was not arterial vasospasm. A full obliteration of the aneurysm sac is observed with a suitable filling of the distal branches of the RMCA. A complete exclusion of the aneurysm was achieved. (C, D) Brain CT scan without contrast medium 48 hours after EVT shows the artifact for the mesh of coils, there was no bleeding or thrombotic complications . (E, F) Brain MRA and coronal TW1+Gd two years and 10 months after the EVT show patency of the RMCA and no recanalization of the aneurysm sac (white arrow).

Revista electrónica publicada por el Departamento de Farmacología de la Escuela de Medicina de la Universidad de Costa Rica, 2060 San José, Costa Rica. ${ }^{\circledR}$ All rights reserved. Licensed under a Creative Commons Unported License. 
Finally and according to the last guidelines of the management of aneurismal subaracnoidal hemorrhage complete obliteration of the aneurysm is recommended whenever possible, the decision of aneurysm treatment, should be a multidisciplinary decision based on characteristics of the patient and the aneurysm and for patients with ruptured aneurysms judged to be technically amenable to both endovascular coiling and neurosurgical clipping, endovascular coiling should be considered too [7].

\section{REFERENCIAS}

1. J. van Dijk, R. Groen, M. Laan, J. Jeltema, J. Mooij, J. Metzemaekers. Surgical clipping as the preferred treatment for aneurysms of the middle cerebral artery. Acta Neurochir Sept 2011; 153:2111-2117.

2. Molyneux AJ, Kerr RS, Birks J, Ramzi N, Yarnold J, Sneade $M$ et al. Risk of recurrent subarachnoid haemorrhage, death, or dependence and standardised mortality ratios after clipping or coiling of an intracranial aneurysm in the International

Subarachnoid Aneurysm Trial (ISAT): long-term follow-up. Lancet Neurol May 2009; 8:427-33.

3. Vendrell JF MD, Menjot N MD, Costalat V MD, Hoa D MD, Moritz J MD, Brunel H MD et al. Endovascular Treatment of 174 Middle Cerebral Artery Aneurysms: Clinical Outcome and Radiologic Results at Long-term Follow-up. Radiology Oct 2009; 253(1):191-198.

4. Vendrell JF, Costalat V, Brunel H, Riquelme C, Bonafe A. Stent-Assisted Coiling of Complex Middle Cerebral Artery Aneurysms: Initial and Midterm Results. AJNR Am J Neuroradiol Feb 2011; 32:25963.

5. Phillips TJ, Dowling RJ, Yan B, Laidlaw JD , Mitchell PJ. Does Treatment of Ruptured Intracranial Aneurysms Within 24 Hours Improve Clinical Outcome? Stroke. Oct 2011; 42:1936-1945.

6. Meckel S, Singh T. Undre'n P, Ramgren B, Nilsson O, Phatouros $\mathrm{C}$ et al. Endovascular Treatment Using Predominantly Stent-Assisted Coil Embolization and Antiplatelet and Anticoagulation Management of Ruptured Blood Blister-Like Aneurysms. AJNR Am J Neuroradiol Apr 2011; 32:764 -71.
7. E.Connolly, A Rabinstein, J Carhuapoma, C Derdeyn, J Dion, R. Higashida et al. Guidelines for the Management of Aneurysmal Subarachnoid Hemorrhage : A Guideline for Healthcare Professionals From the American Heart Association/American Stroke Association. Stroke May 2012;43:1711-1737.

\section{INFORMACION DE AUTOR:}

Rosales Bravo, Luis Guillermo MD. E-mail: luis.rosalesbravo@ucr.ac.cr 